\title{
Twelve hours of a compression sleeve is not enough to improve the muscle recovery of an exercise-damaged upper arm
}

\author{
Mikhail Santos Cerqueira ${ }^{a}$, Lucio Santos Borges ${ }^{a}$, José Alberto dos Santos Rocha ${ }^{a}$, \\ Helder Brito Andrade ${ }^{a}$, Uanderson Silva Pirôpo ${ }^{a}$, Luis Augusto Lupato Conrado ${ }^{b}$, \\ Rafael Pereira ${ }^{a, *}$
}

\footnotetext{
${ }^{a}$ Research Group in Neuromuscular Physiology, Department of Biological Sciences, State University of Southwest Bahia (UESB), Jequie 45210-506, BA, Brazil

b University Camilo Castelo Branco (Unicastelo), Eugênio de Melo 12247-004, São Jose dos Campos, SP, Brazil
}

Received 3 June 2014; accepted 29 July 2014

Available online 23 October 2014

\section{KEYWORDS}

Muscle damage;

Eccentric

contraction;

Compression sleeve;

Elbow flexors;

Rehabilitation

\begin{abstract}
Objective: To assess the efficacy of a compression sleeve worn for a short-time period $(12 \mathrm{~h})$ on the recovery from the symptoms of exercise-induced upper arm muscle damage.

Methods: A randomized controlled study was conducted on thirteen healthy young men using a standardized and exercise-induced upper arm muscle damage protocol, and they were immediately placed into two groups: TREATED $(n=7)$ and CONTROL $(n=6)$. Isometric elbow flexion strength, upper arm circumference, and muscle soreness measurements were taken before and at 24, 48, 72 and $96 \mathrm{~h}$ after the damaging exercise, and were used as criteria of exercise-induced muscle damage. Group comparisons were made for each variable using a two-way ANOVA design ( 2 groups $\times 5$ measurements), and with a significance level of $P<0.05$.

Results: A significant impairment $(P<0.001)$ was observed in muscle strength $(\sim 43 \%$ and $\sim 34 \%$, for CONTROL and TREATED groups, respectively, $24 \mathrm{~h}$ after exercise), as well as a significant increase $(P<0.001)$ in upper arm circumference (UAC) and muscle soreness $\left(F_{4,55}=6.49\right.$ for UAC and $F_{4,55}=6.95$ for muscle soreness) among the measurements after exercise for both groups, with no significant differences between them.

Conclusions: These results, together with previous findings, suggest that the use of a compression garment for $12 \mathrm{~h}$ is not enough to improve the recovery from exercise-induced muscle damage in the upper arm, and longer periods of compression may be necessary to achieve positive outcomes.

(C) 2014 Consell Català de l'Esport. Generalitat de Catalunya. Published by Elsevier España, S.L.U. All rights reserved.
\end{abstract}

\footnotetext{
* Corresponding author.

E-mail address: rafaelpereira@brjb.com.br (R. Pereira).
} 


\section{PALABRAS CLAVE}

Daño muscular;

Contracción

excéntrica;

Manga de

compresión;

Flexores del codo;

Rehabilitación

\section{El uso de manga de compresión durante 12 horas no es suficiente para mejorar la recuperación muscular del brazo tras el daño inducido por el ejercicio}

\section{Resumen}

Objetivo: Evaluar la eficacia de la manga de compresión usada durante un período de tiempo corto $(12 \mathrm{~h}$ ) en la recuperación de los síntomas de daño muscular inducido por el ejercicio de los músculos del brazo.

Métodos: En un estudio aleatorizado controlado, 13 hombres jóvenes sanos realizaron un protocolo de ejercicio estandarizado para inducir daño muscular para los flexores del codo y se dividieron inmediatamente en 2 grupos: tratados $(n=7)$ y control $(n=6)$. Se tomaron medidas de la fuerza isométrica de flexión del codo, la circunferencia del brazo (CB) y la percepción del dolor muscular antes y $24,48,72$ y 96 h después del ejercicio, y se utilizaron como criterios de daño muscular inducido por el ejercicio. Comparaciones entre grupos se hicieron para cada variable con un ANOVA de 2 vías ( 2 grupos $\times 5$ medidas) y con un nivel de significación de $p<0,05$.

Resultados: Se observó una reducción significativa $(p<0,001)$ de la fuerza muscular $(\sim 43 \%$ y $\sim 34 \%$ para el grupo control y tratados, respectivamente, $24 \mathrm{~h}$ después del ejercicio) y un aumento significativo $(p<0,001)$ en la circunferencia del brazo y dolor muscular $\left(F_{4,55}=6,49\right.$ para $C B$ y $F_{4,55}=6,95$ para dolor muscular) a lo largo de las medidas después del ejercicio en ambos grupos, sin diferencias significativas entre ellos.

Conclusiones: Nuestros resultados, junto con los hallazgos previos, sugieren que el uso de la manga de compresión durante $12 \mathrm{~h}$ no es suficiente para mejorar la recuperación de los síntomas de daño muscular inducido por el ejercicio de los músculos del brazo, y para lograr resultados positivos son necesarios largos períodos de compresión.

(C) 2014 Consell Català de l'Esport. Generalitat de Catalunya. Publicado por Elsevier España, S.L.U. Todos los derechos reservados.

\section{Introduction}

Exercise-induced muscle damage (EIMD) after eccentric contractions is a well described condition, which is clinically marked by functional impairments, such as decreased maximal force production capacity, changes in force production optimal length, increased passive tension, and muscle edema. ${ }^{1-3}$ These changes may lead to limitation of athletic performance ${ }^{4,5}$ and increased risk of injury. ${ }^{6}$

The muscle function recovery after damage events is a relevant issue and has attracted attention of many researchers, physical therapists and athletic coaches. Aiming to fostering muscle recovery, contrast water therapy, cryotherapy with ice bags or cold water immersion, low intensity active exercise, phototherapy, massage and compression garment are some recovery strategies employed. ${ }^{5,7-12}$

The use of compressive garments to improve the muscle recovery has shown promising results. ${ }^{10,12,13}$ There are evidences that this treatment modality may promote a more rapid recovery of muscle function, and reduced postexercise muscle soreness and swelling, ${ }^{12,14}$ with potential benefits mediated via physical, physiological or psychological effects, although underlying mechanisms are not well elucidated. ${ }^{14}$

Despite the promising results, it should be noted that the large majority of studies where the compressive garments are employed involve lower limb. In a recent meta-analysis,
Hill et al. ${ }^{12}$ listed twelve studies that achieved established criteria and only three of them ${ }^{13,15,16}$ included the use of compression sleeve worn after damage exercises of upper arm. Interestingly, in these studies the compression sleeve was worn for 72 or $120 \mathrm{~h}$ following damaging exercise, while there are studies reporting effective results wearing compression stockings by only $12 \mathrm{~h}$ following lower limb damaging exercises. . $^{, 10,17}$

It is important to note that the post-exercise recovery strategies should not only be effective, but also promote treatment adhesion, which involves the treatment time necessary to achieve effective results. Notwithstanding, treatment periods of $72 \mathrm{~h}$ or more seem to be long, while treatments for short periods, as $12 \mathrm{~h}$, may improve the treatment adhesion, but, to our knowledge, there are no studies that have investigated the efficacy of compression sleeve worn for short-time periods, as $12 \mathrm{~h}$, on recovery from the symptoms of EIMD from upper arm muscles. This issue gains relevance because upper body exercise results in greater levels of muscle damage and soreness than lower body exercise. ${ }^{18-20}$ Then, it is possible to hypothesize that the use of compression sleeves by short-time periods may not be sufficient to promote an effective recovery as observed when compression garments are applied for lower-body.

Therefore, this study was carried out to assess the efficacy of compression sleeve worn for short-time periods $(12 \mathrm{~h})$, on recovery from the symptoms of EIMD from upper arm muscles. 


\section{Materials and methods}

\section{Participants}

In a randomized controlled study, thirteen subjects, without previous experience with eccentric exercises and who had not performed regular resistance training in the past 6 months, provided informed consent to participate in this study. Ethical approval (protocol \# 06615313.8.0000.0055) was provided by the ethics committee of the State University of Southwest Bahia, according to the Declaration of Helsinki.

Subjects were screened to confirm that they had no neuromuscular diseases and musculoskeletal problems for the non-dominant upper extremity before the study's beginning. Additionally, they were asked to refrain from unaccustomed exercise or vigorous physical activity and not to take any anti-inflammatory drugs or other therapeutic modalities during the experimental period.

\section{Experimental design}

This study was designed to verify the effect of a compressive sleeve, donned immediately after an eccentric exercise bout, on muscle recovery. Subjects were randomly placed into two groups: TREATED $(n=7)$ and CONTROL $(n=6)$, and no significant differences in age, height, body mass were evident between the groups. A crossover experimental design was not used because of the frequent reports about the protective effect promoted by repeated bouts of eccentric exercise. . $^{3,21}$

\section{Eccentric exercise bout}

An eccentric exercise protocol, using weighted dumbbells, was adopted from previous studies.,22 To determine the dumbbell weight for eccentric exercise, each subject was requested to sit on a custom made preacher curl bench with his shoulder joint angle at $45^{\circ}$ flexion with $0^{\circ}$ abduction, and pull a handle attached to a load cell (EMG System, São Jose dos Campos, Sao Paulo, Brazil) using the non-dominant arm.

The elbow joint angle was set at $90^{\circ}$, and the subject was asked to flex the elbow joint maximally while keeping the forearm supinated. This measurement was taken three times immediately before the eccentric exercise, with a 45-s rest between trials, and the average peak force from the three trials was used to determine the dumbbell weight. No significant difference in dumbbell weight was found between the groups (see Table 1).

Once the load of the dumbbell was determined, the subjects were instructed to lower the dumbbell from an elbow flexion of $50^{\circ}$ to an extended position of $170^{\circ}$ in approximately 4-5s, when the investigator removed the dumbbell from the arm, and the subject returned the arm to the start position for the next eccentric contraction. Subjects were verbally encouraged and guided to lower the dumbbell at a consistent velocity by following a count given by the investigator. The movement was repeated 30 times with a $45-\mathrm{s}$ rest between contractions.
Table 1 Mean \pm SE of anthropometric characteristics, exercise load, and baseline values of muscle soreness and UAC from TREATED and CONTROL groups.

\begin{tabular}{lrcl}
\hline & TREATED & CONTROL & $P$ \\
\hline Age (years) & $22 \pm 1$ & $20 \pm 1$ & 0.104 \\
Height $(\mathrm{cm})$ & $173 \pm 2$ & $174 \pm 3$ & 0.776 \\
Weight $(\mathrm{kg})$ & $71 \pm 7$ & $71 \pm 7$ & 0.977 \\
$\quad$ Isometric muscle & $167 \pm 8$ & $204 \pm 20$ & 0.137 \\
$\quad$ strength $(\mathrm{N})$ & $17 \pm 1$ & $20 \pm 2$ & 0.137 \\
Exercise load $(\mathrm{kg})$ & $0 \pm 0$ & $0 \pm 0$ & - \\
Muscle soreness (mm) & $25.9 \pm 1$ & $27.0 \pm 1.6$ & 0.576 \\
UAC $(\mathrm{cm})$ & & &
\end{tabular}

\section{Intervention}

Immediately after the eccentric exercise bout the volunteers donned a sleeve compression (group TREATED) or no intervention (group CONTROL). Volunteers were randomized by using a simple drawing of lots (A and B), and those allocated into the lot $A$ received a compression sleeve (group TREATED) while those into the lot $B$ received none intervention (group CONTROL).

The subjects in the TREATED group wore the compression sleeve for $12 \mathrm{~h}$ following the eccentric damage protocol and were only allowed to remove for bathing to ensure that the total time out of the compression garment did not exceed $30 \mathrm{~min}$. Compression sleeve was made with $90 \%$ polyamide and $10 \%$ lycra (elastane) fibers, and covered the non-dominant arm from axillary line to mid-forearm.

\section{Dependent variables}

The dependent variables consisted of elbow flexion peak force with the elbow joint angle set at $90^{\circ}$, upper arm circumference (UAC) and muscle soreness. The isometric muscle strength, UAC, and muscle soreness measures were taken before and at 24, 48, 72 and $96 \mathrm{~h}$ after eccentric exercise.

\section{Isometric muscle strength}

The isometric muscle strength was recorded as described previously to determine the dumbbell weight. All isometric muscle strength measures were taken before, and at 24 , 48,72 and $96 \mathrm{~h}$ after the eccentric exercise bout. The highest peak force among the three trials from each day was used for statistical comparisons, and the isometric muscle strength recorded at 24-96h after exercise bout was normalized by the measure recorded before the exercise bout to allow comparisons between groups.

\section{Upper arm circumference (UAC)}

Upper arm circumference was assessed at $8 \mathrm{~cm}$ above the elbow joint with a Gulick tape measure, while the subject was standing and allowing the arm to hang down by the side of the hips. The measurement point was marked on the subject's arm to ensure consistent placement of the tape 
measure, and the average value of three measurements was used for further analysis, as used by Chen et al. ${ }^{3}$ The same experienced investigator assessed the UAC over time for all subjects to ensure the reliability of measures.

\section{Muscle soreness}

The level of muscle soreness of the exercised arm was assessed using a visual analog scale (VAS) consisting of a $100-\mathrm{mm}$ line representing "no pain" at one end $(0 \mathrm{~mm})$ and "very, very painful" at the other $(100 \mathrm{~mm})$. The subjects were asked to indicate the level pain on the line when the investigator extended the elbow joint maximally. The same investigator assessed the muscle soreness over time for all subjects, and the procedure was standardized as described in previous studies. ${ }^{3,22}$

\section{Statistical analysis}

The anthropometric characteristics and exercise load (i.e., dumbbell weight for exercise bout), as well as the baseline measures of Isometric muscle strength, muscle soreness and UAC from groups were compared with unpaired student $t$ test. For elbow flexion peak force and UAC the measures after exercise bout and intervention were normalized using each subject' own initial baseline (i.e., measure before exercise bout and intervention) measurement as reference. Dependent variables were assessed with a two-way model analysis of variance ( 2 groups $\times 5$ times) with repeated measures over time points and group as between-subjects factors to compare the normalized force, normalized UAC and VAS for the groups (TREATED and CONTROL) following exercise bout. Multiple comparisons were made according to Bonferroni's method $(0.05 /$ number of comparisons). A significance level of $P<0.05$ was used for all statistical procedures. Results are presented as mean \pm SE. Statistical analysis was completed using the PASW 18 statistical package (SPSS Inc., Chicago, IL).

\section{Results}

Anthropometric characteristics and the exercise load (i.e., dumbbell weight for the exercise bout) from the TREATED and CONTROL groups were not different. Similar baseline values were also observed for muscle soreness and UAC (see Table 1).

For the normalized force, a significant main effect for measures $\left(F_{4,55}=5.51 ; P=0.001\right)$ was observed. Normalized force decreased significantly after the eccentric exercise bout for both groups, reaching impairments of $\sim 43 \%$ and $\sim 34 \%$, for CONTROL and TREATED groups, respectively, $24 \mathrm{~h}$ after exercise. Despite of this, a significant main effect for groups or group measure interactions was not observed (see Fig. 1A).

Upper arm circumference and muscle soreness showed a significant main effect for measures $\left(F_{4,55}=6.49 ; P<0.001\right.$ for UAC and $F_{4,55}=6.95 ; P<0.001$ for muscle soreness), with an increase after exercise bout for both groups. Furthermore, no significant main effect for groups or group $\times$ measure interactions was observed (see Fig. 1B and C).

\section{Discussion}

The primary finding of this investigation was that the use of a compression sleeve for short-time period $(12 \mathrm{~h})$ was not effective to improve the recovery from the symptoms of EIMD from upper arm muscles. This finding is in line with our hypothesis that compression sleeve worn for short-time periods may not be sufficient to promote an effective recovery from EIMD, what diverge when lower-body compression garments are applied.

Benefits from compression garments may be mediated by creating an external pressure gradient, which partially compensate changes in osmotic pressure and reduces the space available for swelling. ${ }^{12,23,25}$ Despite speculative aspect of this hypothesis, it could explain positive results from compressive garments, decreasing exudates and the degree of chemotaxis, thus attenuating the inflammatory response and perceived pain. ${ }^{12,23}$

Although the underlying mechanisms are not well elucidated, the use of compression garments to enhancing recovery from muscle damage has been recognized, ${ }^{12}$ but positive results are predominantly observed when compression garments are employed for lower limb, ${ }^{12}$ while for the upper arm there are only two studies with positive results. ${ }^{13,16}$

Kraemer et al. ${ }^{16}$ submitted healthy young women to an upper-arm damaging exercise (elbow flexors) and allocated them into two groups, a control group (i.e., none intervention) and an intervention group, that used a compressive sleeve throughout a recovery period of 5 days (i.e., $120 \mathrm{~h}$ ). These authors observed a significant recovery from the symptoms of EIMD (prevented loss of elbow motion, decreased perceived soreness, reduced swelling, and promoted recovery of force production), suggesting a benefic effect of compressive sleeve. However, it is important to note that, in the cited study, significant differences between groups for force production and perceived soreness were observed predominantly after the third day of recovery period, which correspond to a $\sim 72 \mathrm{~h}$ of continuous compressive sleeve use.

Similar results were found from Kraemer et al., ${ }^{13}$ but involving healthy young men and the use of compressive sleeve for $72 \mathrm{~h}$. Interestingly, Carling et al. ${ }^{15}$ found no differences in recovery from EIMD (perceived soreness, range of motion (ROM), arm circumference, and force production) of upper arms (elbow flexors) between control and compression sleeve used for $72 \mathrm{~h}$.

Such results suggest a potential benefit from the use of compressive sleeve in recovery from EIMD, but it has been tested only with compression sleeves worn for long periods (i.e., $72 \mathrm{~h}$ or more), while many studies showed positive results when compression stockings are used for $12 \mathrm{~h}$ fol-

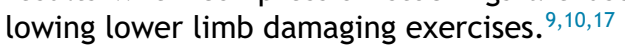

In this context, we assessed the efficacy of compression sleeves worn for short-time periods $(12 \mathrm{~h})$ on recovery from the symptoms of EIMD from upper arm muscles and found that it was not effective to improve the recovery. Our results confirm the suggested hypothesis that short-time 

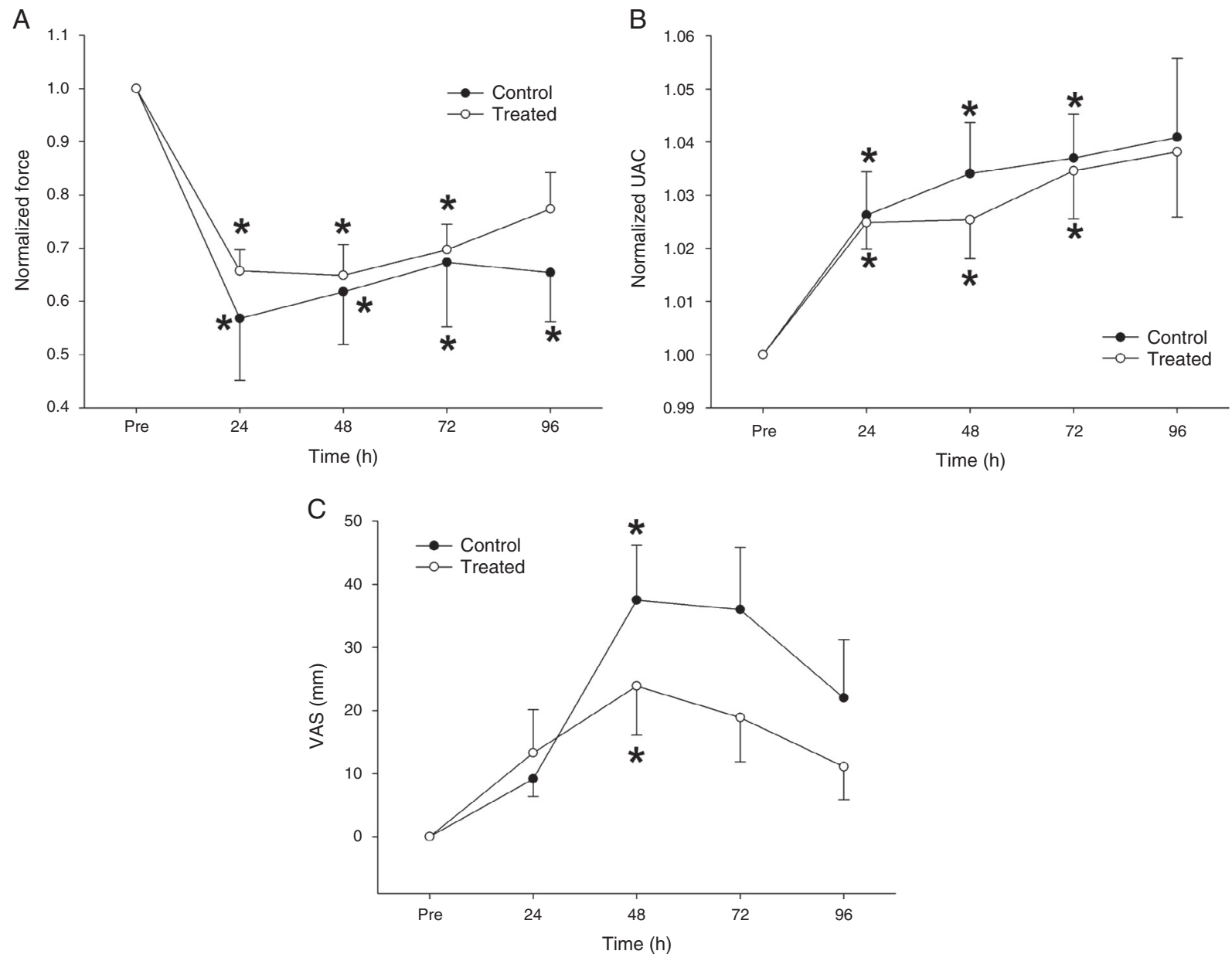

Figure 1 Mean \pm SE of normalized force $(A)$, normalized upper arm circumference $(B)$ and muscle soreness $(C)$ from TREATED and CONTROL groups before (PRE), and 24, 48, 72 and $96 \mathrm{~h}$ after an eccentric exercise bout. *Significantly different from measure PRE $(P<0.05)$.

periods of compression sleeve may not result in effective results as observed when lower-body compression garments are applied.

It is known that upper body exercise results in greater levels of muscle damage and soreness than lower body exercise, ${ }^{18-20}$ and this different muscle susceptibility to EIMD (mainly with eccentric actions) may result from the different architecture of arm and leg muscles, ${ }^{24}$ such that mechanical stress per muscle unit differs between these two muscle groups when performing exercises at the same intensity (i.e., a percentage of maximum).

Additionally, Jamurtas et al. ${ }^{18}$ proposed that submaximal eccentric actions of lower body muscles, such as downhill walking and descending stairs, are routinely performed during daily activities and it is well documented that, following repeated bouts of eccentric exercise, the muscles adapt to protect against further damage. ${ }^{26}$ This difference in the susceptibility to EIMD from upper and lower limb muscles may explain our findings, such that the same intervention, as the use of compressive garments, applied with the same parameters, may not produce similar outcomes. As for many other therapeutic interventions, the time to exposure or treatment may influence the outcome, and for compression sleeves, the minimum intervention period seems to be greater than $12 \mathrm{~h}$. Further studies should focus on this issue: What is the minimum intervention time with compression sleeves to fostering muscle recovery after damaging exercises?

\section{Conclusion}

Our results, together with previous findings, suggest that $12 \mathrm{~h}$ of compressive garment is not enough to improve the recovery from EIMD in upper arm muscles, and longer periods of compressive garment should be necessary to achieve positive outcomes.

\section{Conflict of interest}

Authors declare that they don't have any conflict of interests.

\section{Acknowledgments}

Mikhail Santos Cerqueira, Lucio Santos Borges and José Alberto dos Santos Rocha would like to thank Conselho Nacional de Desenvolvimento Científico e Tecnológico 
(CNPq), Fundação de Amparo à Pesquisa do Estado da Bahia (FAPESB) and Universidade Estadual do Sudoeste da Bahia (UESB), respectively, for the scholarship concession (\# 046/2012).

\section{References}

1. Morgan DL, Allen DG. Early events in stretch-induced muscle damage. J Appl Physiol. 1999;87:2007-15.

2. Proske U, Morgan DL. Muscle damage from eccentric exercise: mechanism, mechanical signs, adaptation and clinical applications. J Physiol. 2001;537:333-45.

3. Chen TC, Chen HL, Lin MJ, Wu CJ, Nosaka K. Potent protective effect conferred by four bouts of low-intensity eccentric exercise. Med Sci Sports Exerc. 2010;42:1004-12.

4. Byrne C, Eston R. The effect of exercise-induced muscle damage on isometric and dynamic knee extensor strength and vertical jump performance. J Sports Sci. 2002;20:417-25.

5. Gill ND, Beaven CM, Cook C. Effectiveness of post-match recovery strategies in rugby players. Br J Sports Med. 2006;40:260-3.

6. Cheung K, Hume PA, Maxwell LL. Delayed onset muscle soreness treatment strategies and performance factors. Sports Med. 2003;33:145-64.

7. Liu XG, Zhou YJ, Liu TC, Yuan JQ. Effects of low-level laser irradiation on rat skeletal muscle injury after eccentric exercise. Photomed Laser Surg. 2009;27:863-9.

8. Barnett A. Using recovery modalities between training sessions in elite athletes: does it help? Sports Med. 2006;36:781-96.

9. Jakeman JR, Byrne C, Eston RG. Lower limb compression garment improves recovery from exercise-induced muscle damage in young, active females. Eur J Appl Physiol. 2010;109:1137-44.

10. Jakeman JR, Byrne C, Eston RG. Efficacy of lower limb compression and combined treatment of manual massage and lower limb compression on symptoms of exercise induced muscle damage in women. J Strength Cond Res. 2010;24:3157-65.

11. Leeder J, Gissane C, Someren K, Gregson W, Howatson G. Cold water immersion and recovery from strenuous exercise: a metaanalysis. Br J Sports Med. 2012;46:233-40.

12. Hill J, Howatson G, Someren K, Leeder J, Pedlar C. Compression garments and recovery from exercise-induced muscle damage: a meta-analysis. Br J Sports Med. 2014;48:1340-6.

13. Kramer WJ, Bush JA, Wickham RB, Denegar CR, Gomez AL, Duncan NB, et al. Continuous compression as an effective therapeutic intervention in treating eccentric-exercise induced muscle soreness. J Sport Rehabil. 2001;10:11-23.

14. MacRae BA, Cotter JD, Laing RM. Compression garments and exercise: garment considerations, physiology and performance. Sports Med. 2011;41:815-43.

15. Carling J, Francis K, Lorish C. The effects of continuous external compression on delayed-onset muscle soreness (DOMS). Int J Rehabil Health. 1995;1:223-35.

16. Kraemer WJ, Bush JA, Wickham RB, Denegar CR, Gomez AL, Gotshalk LA, et al. Influence of compression therapy on symptoms following soft tissue injury from maximal eccentric exercise. J Orthop Sports Phys Ther. 2001;31:282-90.

17. French DN, Thompson KG, Garland SW, Barnes CA, Portas MD, Hood PE, et al. The effects of contrast bathing and compression therapy of muscular performance. Med Sci Sports Exerc. 2008;40:1297-306.

18. Jamurtas AZ, Theocharis V, Tofas $T$, Tsiokanos A, Yfanti C, Paschalis V, et al. Comparison between leg and arm eccentric exercises of the same relative intensity on indices of muscle damage. Eur J Appl Physiol. 2005;95:179-85.

19. Chen TC, Lin KY, Chen HL, Lin MJ, Nosaka K. Comparison in eccentric exercise-induced muscle damage among four limb muscles. Eur J Appl Physiol. 2011;111:211-23.

20. Machado M, Brown LE, Augusto-Silva P, Pereira R. Is exercise-induced muscle damage susceptibility body segment dependent? Evidence for whole body susceptibility. J Musculoskelet Neuronal Interact. 2013;13:105-10.

21. Nosaka K, Sakamoto K, Newton M, Sacco P. How long does the protective effect on eccentric exercise-induced muscle damage last? Med Sci Sports Exerc. 2001;33:1490-5.

22. Chen TC, Nosaka K, Sacco P. Intensity of eccentric exercise, shift of optimum angle and the magnitude of repeated bout effect. J Appl Physiol. 2007;102:992-9.

23. Kraemer WJ, French DN, Spiering BA. Compression in the treatment of acute muscle injuries in sport. Int Sport Med J. 2004;5:200-8.

24. Lieber RL, Friden J. Functional and clinical significance of skeletal muscle architecture. Muscle Nerve. 2000;23: 1647-66.

25. Davies V, Thompson KG, Cooper SM. The effects of compression garments on recovery. J Strength Cond Res. 2009;2: 1786-94.

26. Clarkson PM, Hubal MJ. Exercise-induced muscle damage in humans. Am J Phys Med Rehabil. 2002;81:S52-69. 